\title{
Editorial
}

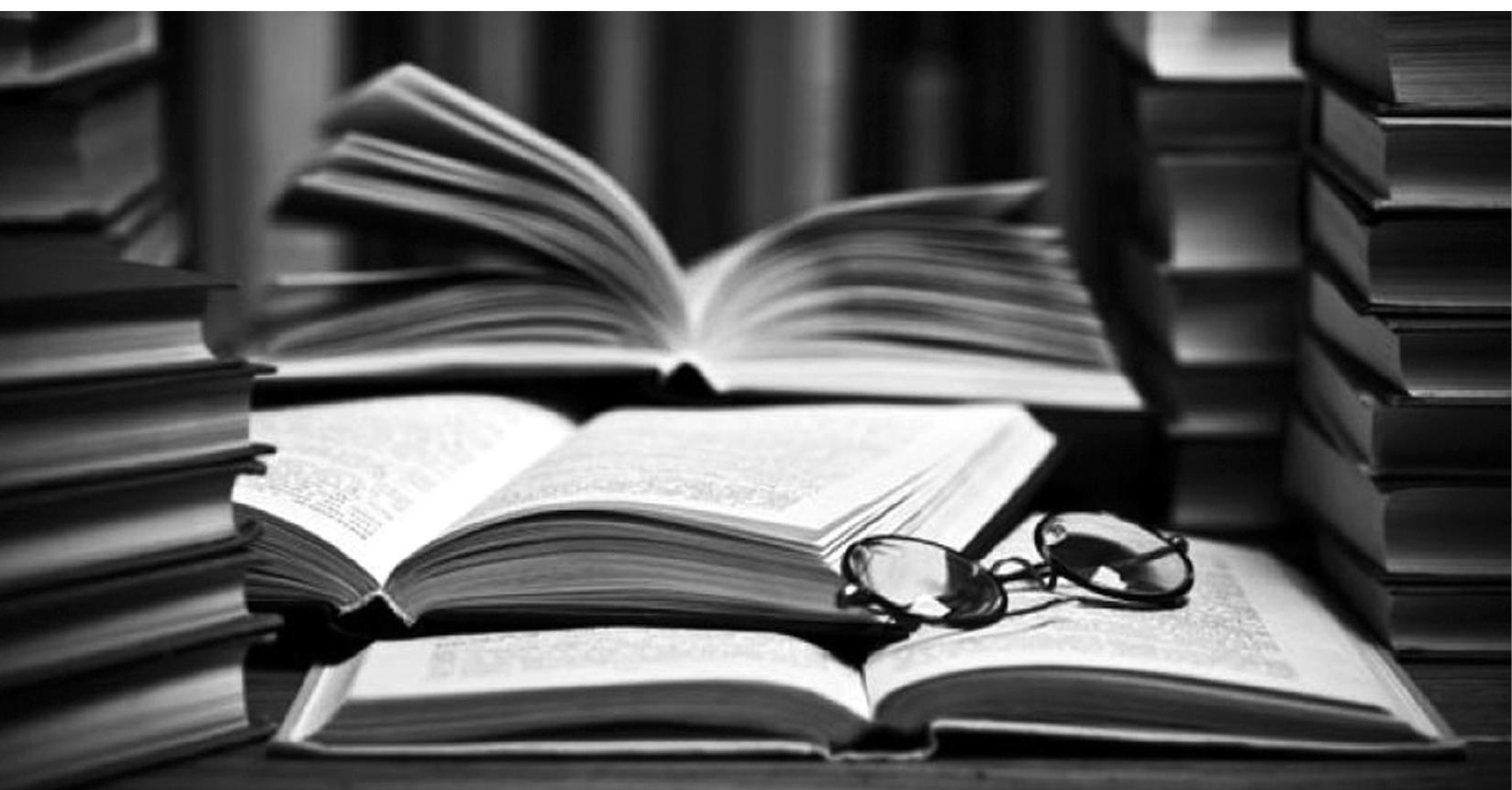





\section{Hablemos de Corrupción}

Entendemos por corrupción aquella acción humana que transgrede las normas legales y los principios éticos, su objetivo es hacerse de un beneficio económico indebido con consecuencias que afectan gravemente al desarrollo social.

La magnitud de la afectación social es tal, que podría ejemplificarse como el veneno que corroe a las instituciones del Estado e indudablemente deteriora su salud al extremo de causarle la muerte.

Son la corrupción y la impunidad, los grandes males que nos aquejan, porque rompen con el principio de legalidad y ello resta credibilidad, debilita y atormenta al Estado de Derecho, convirtiendo el tema en un problema de gobernabilidad.

Un Estado Social y Democrático de Derecho es la antítesis de un Estado corrupto, esto es así, porque en el primero se coloca al ciudadano en el centro y motor de sus intereses, posicionando el interés colectivo en el objetivo y meta por alcanzar, en cambio en el Estado Corrupto, lo primordial es satisfacer el interés de unos cuantos, sin importar el daño y prejuicio provocado a la gran mayoría.

En efecto, la dignidad humana y el desarrollo integral de las personas son metas que persigue el Estado Social y Democrático de Derecho a través de todas sus instituciones, las cuales trabajan y se interrelacionan conformando planes a corto, mediano y largo plazo, así como programas estructurales que respetan en todo momento los derechos humanos, el principio de legalidad y la absoluta transparencia de los recursos públicos.

En cambio, en un Estado Corrupto, donde lo importante es el beneficio económico irregular, tramposo y oculto en prejuicio del resto de ciudadanos, ¿cómo podría una sociedad perdurar en el tiempo?, más aún, ¿cómo podría crecer, desarrollarse y progresar sin recursos públicos? La respuesta es simple: No podría.

En esa relación de ideas, significa que el Estado corrupto esta destinado 
a disolverse o refundarse, en definitiva, no es posible que una sociedad pueda crecer, desarrollarse y progresar con corrupción.

Ese es el grave problema de los casos de corrupción, más allá de las consideraciones éticas o filosóficas, la corrupción trastoca y deteriora en su totalidad el propósito y esencia del Estado, afectando mientras tanto de manera directa y contundente a los grupos vulnerables que conforman la sociedad.

Por citar algunos ejemplos de los casos multimillonarios de corrupción en México: El Caso $O H L$, en donde se conoció que ejecutivos de esta compañía acordaban supuestos aumentos de peaje en autopistas del Estado de México a cambio de pagar las vacaciones de un funcionario estatal; o el Caso de la Casa Blanca, en donde se supo que Enrique Peña Nieto tiene una casa de 86 millones de pesos en las lomas de Chapultepec, construida por la empresa Higa, una de las empresas que ganó la licitación del tren México-Querétaro, y que antes llevó a cabo obras cuando él fue gobernador.

También tenemos El caso de Guillermo Padrés, ex gobernador de Sonora, durante su gestión se detectó una quiebra del sector salud, dobles nóminas, falta de infraestructura educativa y de bienes como camiones, así como daños en la infraestructura carretera a pesar de que hubo dinero para mantenimiento, también irregularidades fiscales al 'perdonar' el pago de impuestos a empresas en las que participan socios, amigos y familiares de colaboradores; o El Caso César Duarte quien ha sido cuestionado por el manejo económico del estado de Chihuahua: Al inicio de su administración la deuda sumaba 12 mil 547 millones de pesos. Ahora, el monto ascendió a los 41 mil 309 millones de pesos.

Otro caso, El de Oceanografía en donde Banamex, filial del gigante financiero estadounidense Citigroup, denunció un fraude de 585 millones de dólares operado mediante la entrega en garantía de documentos falsos de Pemex. El único empresario detenido por corrupción fue Amado Yáñez, dueño de la empresa Oceanografía.

Por su parte en el ámbito internacional destaca la Organización de Cooperación y Desarrollo Económicos (OCDE) quien ubica a México en el último lugar, de igual manera entre los países que integran el Acuerdo Estratégico Transpacífico, (TPP), se sitúa a México en el último lugar.

Por otra parte, el Índice de Percepción de la Corrupción (IPC) señala que 
México cayó en 201628 lugares, situándose en el lugar 123 de 176 naciones evaluadas, sus socios comerciales Canadá y Estados Unidos ocupan los lugares 82 y 74 respectivamente.

Todo ello a encendido los focos rojos en el contexto internacional, México pierde credibilidad y confianza en el entorno internacional, lo cual afecta considerablemente acuerdos y tratos comerciales.

La otra cara de la moneda la ofrece el Consejo Nacional de Evaluación de la Política de Desarrollo Social (CONEVAL) quien tiene unas cifras nada halagüeñas en lo que se refiere a la situación de pobreza en México en el año 2016 equivale al $43.6 \%$ de la población y un rezago educativo del 17.4\%; un rezago en Seguridad Social del 55.8\% y un rezago en el acceso a la salud del $15.5 \%$; en la vivienda del 19.3\%; en la alimentación del 20.1\%; con todo ello, se sitúa al 50.6\% de los mexicanos con un ingreso inferior a la línea de bienestar.

Cifras indudablemente indignantes, si comparamos los miles de millones de pesos obtenidos por actos de corrupción en México, frente a las necesidades para otorgar por lo menos un rango de bienestar mínimo a la mitad de la población en México.

Ante esta realidad, el Estado Mexicano ha emprendido una construcción institucional para combatir la corrupción, siguiendo la Convención Interamericana contra la Corrupción de la Organización de Estados Americanos y la Convención de las Naciones Unidas contra la Corrupción, así como la Convención para combatir el Cohecho de la Organización de Cooperación y Desarrollo Económico.

Por lo que en mayo de 2015 se incluye en el artículo 113 Constitucional el Sistema Nacional Anticorrupción que se define como: "La instancia de coordinación entre las autoridades de todos los órdenes de gobierno competentes en la prevención, detección y sanción de responsabilidades administrativas y hechos de corrupción, así como en la fiscalización y control de recursos públicos".

Es hasta julio de 2016, cuando se expide la Ley General del Sistema Nacional Anticorrupción, de orden público y de observancia general en todo el territorio nacional, que junto con la Ley General de Responsabilidades Administrativas y la Ley Orgánica del Tribunal de Justicia Administrativa tienen el objetivo de prevenir, investigar y sancionar las faltas administrativas y los actos de corrupción en México. 
Este año 2018 iniciamos con la puesta en marcha el Sistema Estatal Anticorrupción en Jalisco. Los retos son muchos y un buen inicio sería vernos y reconocernos en conjunto como parte importante para evitar la corrupción. Sólo con el fortalecimiento que hagamos cada uno de nosotros del principio de legalidad podremos recuperar nuestra confianza y nuestra identidad.

Empoderarse es la clave para salir de tan penoso conflicto ético. Todos los ciudadanos debemos respetar en el Estado de Derecho y actuar en consecuencia, consideremos que el fin ultimo de todas las instituciones, somos nosotros: los ciudadanos; por ello, es el momento de participar en los planes, programas y estrategias de todas las instituciones públicas para de manera transparente lavar nuestra ropa sucia.

Invierno 2018

Dra. Silvia Patricia López González

Directora- Editora 